\title{
Realisation of the right to health and safety at work in the Republic of Macedonia
}

\begin{abstract}
The right to health and safety at work is the most important right in protecting workers at work. In Macedonia, this is regulated by a group of laws, among which the most important is the Law on Safety and Health at Work. These laws contain modern norms which aim to guarantee the efficient protection of workers in the workplace. However, in the Republic of Macedonia such provisions as are contained in these laws are insufficiently applied in practice. The authors' view is that the reasons for this can, basically, be reduced to three groups, i.e: the lack of a general legal culture; a lack of discipline in operation; and a lack of resources to purchase and maintain funds for professional safety and for enforcement measures for this purpose. Macedonian society has the possibility to establish an effective system of protection for workers' health and safety, provided that the state lays down proper mechanisms for its delivery. Nevertheless, in such a system, the main change agent will continue to be the educational institutions of society (family, schools, universities, etc.).
\end{abstract}

Keywords: safety, healthy work, worker protection, legislation, normative framework, employer and employee duties, safety representatives, labour inspection, collective agreements, rule of law, resource gap

\section{Introduction}

The right to health of human beings is a natural right. Viewed dialectically, this stems from the right to life and is directly connected with this right. In preserving health against illnesses and injuries, human beings maintain their lives because diseases and injuries can kill. Healthy people are productive: they produce new goods and create new value. In this way - in producing and creating - they participate in state-building as a social community and participate in its social progress.

Keeping this in mind, states, as social communities, have been deeply interested in the health of their citizens and have been taking all the measures which are necessary for the protection of health from the earliest times up to the present day. ${ }^{1}$

Looking at the issue from a socio-legal perspective, the right to health is a social human right. Consequently, the right to health is the right to an individual's own health as the normal natural state of a human being, as an individual in the community. The

1 In this connection, see V. Spirkoski and T. Risteski 'The right to health and the role of the state in its realization' Proceedings of $1^{\text {st }}$ Croatian Congress on Preventive Medicine and Health Promotion, 26-29 November 2003. 
right to an individual's own health does not imply a right to be healthy because to be healthy is not dependent on the individual. To be healthy means to be in a naturally healthy situation, which does not depend only on the individual's desire but on the natural environment. On this basis, the right to health must be understood as a right to enjoy 'The highest attainable standard of physical and mental health'. ${ }^{2}$

The right to the protection of one's health is in an immediate dialectical correlation with the right to safety at work. In the absence of the latter, injuries, occupational diseases and, in extreme cases, even the death of an employee are all possible outcomes.

The International Covenant on Economic, Social and Cultural Rights, based on the theory of the natural law of human rights, obliges member states to recognise the right of each individual to the enjoyment of just and favourable working conditions and, in the framework of this, the right to health and safety; the right to healthy working conditions; and the right to rest, leisure time and the reasonable limitation of working hours, as well as periods of paid leave. ${ }^{3}$

The Republic of Macedonia, according to its aspirations to join the democratic world as an equal participant in all the related processes which occur in it, and especially by its aspiration to join the European family of peoples integrated in the European Union, has accepted and promptly ratified all international legal instruments - declarations, conventions, treaties and others - implementing these in its legal system.

The Constitution of the Republic of Macedonia, under the provisions of Article 32, Paragraph 1, guarantees its citizens the right to work; to free choice of employment, to protection at work; and to material assistance during temporary unemployment. Bearing in mind the subject of this article, we focus here only on the right to protection at work. This right is based on the constitutional guarantee of the physical and moral integrity of the individual, as a sacrosanct value of human beings, contained in Article 11, Paragraph 1 of the Constitution. Furthermore, Paragraph 5 of Article 32 provides the basis for a closer regulation of the legal elements related to this protection, which can be developed by law and by collective agreements. In any case, the most important element of this protection are working conditions, the immediate protection of health during work, the prohibition of work dependent on age and gender, and the limitation of working hours.

2 Article 12, Paragraph 1 of the International Covenant on Economic, Social and Cultural Rights; Dr. Zvonimir Jankulovski (1993) Human Rights, A Collection of Documents edited by the Fund for Open Society in Macedonia: Skopje.

3 According to Article 7 of the International Covenant on Economic, Social And Cultural Rights, states parties are obliged to recognise the right of everyone to the enjoyment of just and favourable conditions of work, which ensures, in particular: (a) remuneration which provides all workers, as a minimum, with: (1) fair wages and equal remuneration for work of equal value without distinction of any kind, in particular women being guaranteed conditions of work not inferior to those enjoyed by men, with equal pay for equal work; (2) a decent living for themselves and their families in accordance with the provisions of the Covenant; (b) safe and healthy working conditions; (c) equal opportunity for everyone to be promoted in their experience of employment to an appropriate higher level, subject to no considerations other than those of seniority and competence; (d) rest, leisure and reasonable limitation on working hours and periodic holidays with pay, as well as remuneration for public holidays. 
Regarding the right to safe and healthy work, the guarantee of health protection embodied in Article 39, Paragraph 1 of the Constitution must definitely be borne in mind. This guarantee is achieved primarily by the exercise of constitutional rights, while it is the constitutional duty of every citizen of the Republic to protect and improve their own health and the health of others, set out in Paragraph 2 of this Article.

On the basis of the constitutional provisions, the Assembly of the Republic of Macedonia has passed a number of laws that regulate the protection of the right of citizens during work.

One of the most important laws which regulate this right is, without doubt, the Law on Safety and Health at Work, adopted by the Assembly of the Republic of Macedonia in mid-2007. ${ }^{4}$

In addition to this law, provisions on health and safety at work are contained in other laws such as, among others, the Law on Labour Relationships; the Law on Environmental Protection; the Law on Explosive Substances; the Law on the Quality of the Air; the Law on Ionising Radiation and Radiation Safety; the Law on Protection against Smoking; the Law on Labour Inspection; and the Law on Health and Sanitary Inspection. Provisions on health and safety at work are also contained in collective agreements including the General Collective Agreement for the Republic of Macedonia; the General Collective Agreement for the Private Sector in the Economy in the Republic of Macedonia; and the General Collective Agreement for Civil, Judicial and Local Authorities.

Measures for achieving the right to health and safety at work in the Republic of Macedonia

\section{Law on Safety and Health at Work}

The Law on Safety and Health at Work is the lex generalis for safety problems and the protection of the health of workers in the performance of their duties and tasks at work. According to the Law, health and safety at work is accomplished via the preventive measures taken and planned, at all levels of work, by employers in the prevention or reduction of risks to the health and safety of employees in the workplace. The Law sets out that safe working conditions are achieved by the application of contemporary technological, organisational, legal, social, health-based and other measures, and by the use of appropriate technical means.

Measures taken are designed to ensure:

- planning, organising and reviewing protection at work in accordance with modern scientific methods and achievements

- designing, building and maintaining works premises in accordance with the nature of work and the use of prescribed measures, norms and standards for safe working practices

4 The Law is published in the Official Gazette of the Republic of Macedonia, No. 92/07. Following adoption, the Law was amended five times with amendments published in the Official Gazette of $R M$, Nos. $136 / 11 ; 23 / 13 ; 25 / 23 ; 137 / 13$; and 164/13. 
- adjusting working conditions in line with human physical and psychological traits and abilities, and providing technology and forms of work organisation that will facilitate the performance of work tasks in line with the most favourable posture

- maintaining and equipping office premises in a manner that will eliminate the potential dangers of diseases and injuries of workers stemming from work or workrelated tasks

- designing, installing, using and maintaining tools, equipment, devices, means of personal protection and safety and other operating assets in order that workers may carry out their work duties in a manner that will provide adequate safety for workers

- limiting the use of harmful and dangerous substances that can cause occupational diseases or injuries at work

- using tools and personal protective equipment at work when necessary.

The Law divides into general and special obligations those duties of employers which are related to the exercise of workers' rights to their health and safety at work.

General obligations include those which are taken in all technological work processes to ensure the protection of people carrying out work tasks or otherwise participating in them. They include:

- protection from the impact of electricity, harmful radiation, noise and vibrations, as well as hazardous and harmful substances

- protection against fires and explosions

- use of the means for personal protection and safety, and protective equipment

- the provision of hygienic and healthy conditions at work

- providing for transportation and the movement of workers in the performance of work

- ensuring that tools are fitted with protective devices

- protection against harmful environmental and atmospheric influences (moisture, cold and heat), and first aid in cases of injury and illness.

The special obligations of employers in relation to the exercise of the right to workers' health and safety are applied in the specific circumstances of work in various industries or sectors, such as working outdoors (in construction and in agriculture, forestry, etc.); work taking place under water (diving and other activities carried out in a situation of changed air pressure); working underground (tunnel construction, and so on); working at height; and certain works in road, rail, air and water transport, especially concerning dangers in the areas of operation and movement. These measures are prescribed by laws, rules and guidelines, etc. that are passed by the Minister of Labour and Social Policy, unless they are otherwise prescribed by another law.

The Law obliges employers to regulate certain relationships, rights, obligations and responsibilities in the area of the operational implementation of measures for protection at work. In practice, such regulation is usually made in the form of instructions, orders or decisions. Based on them, employers must determine, or prescribe, those jobs that carry a high risk of injury or illness (jobs with special conditions and specific criteria that must be met in the recruitment and selection of candidates, i.e. workers). This refers to age, expertise and other mental and physical abilities. 
The specific duties required of an employer are as follows:

- train employees (both theoretically and in practice) as regards high-risk activities in order to reduce the risk of adverse consequences. The legal obligation of the employer is to provide training to workers in employment, to re-deploy their employees in cases of changes in the technological process of work, and so on

- provide appropriate protective equipment and ensure its timely maintenance, including as regards personal protection devices

- provide adequate working tools which are submitted to inspections that verify their appropriateness

- protect workers during night work (deliver technical and health care, transportation, food, etc.)

- appoint officials who are responsible for implementing the measures prescribed for protection at work

- implement preventive measures against fire and measures for the evacuation of workers in unforeseen dangerous circumstances, provide first aid, etc.

- be accountable in cases of deviation from these protective measures via the nomination of a qualified person concerning the non-implementation of protective measures for workers and damage-dissipation materials, defects, tools and devices

- ensure the employee's temporary removal from the workplace if the employer does not comply with the prescribed measures for protection at work and, as a result, seriously endangers their health and their lives, the health and lives of other workers, the employer's property or the environment

- ensure the preliminary and periodical medical examination of workers which, according to this Law, should be carried out by competent health authorities, with a systematic review at least once every eighteen months. ${ }^{5}$

In the case of changes, modifications or amendments to the laws, bylaws, rules and regulations, the employer is obliged to apply these in practice and to deliver the theoretical and practical training required for each worker.

The employer is also required under this Law to conduct a technical examination of working equipment, appliances and tools, etc. to ensure their safety of use and to provide the appropriate test certificates which guarantee their appropriateness as well as the personal safety of the users.

In the prevention or treatment of injuries and occupational illnesses, evidence in the area of protection at work assumes significant importance. The purpose of such evidence is to provide information as regards vocational training and the qualification levels of employees for working safely; for examinations carried out on tools; for tests conducted on harmful effects of a physical, chemical and biological nature, as well as

5 This applies especially in jobs in which there is an increased risk of injuries and ailments, or occupational illnesses threatening the health of workers (working in heightened or lowered air pressure, or at high or low temperatures; where there is harmful radiation, or increased levels of vibration, etc.). Specific workplaces that contain special health needs, or which make psychophysical demands on workers (working in conditions of insufficient or strong illumination, working in premises contaminated with harmful chemical substances, working underground or underwater, etc.), are also encompassed by these procedures, as are workplaces where there is no possibility of the existing measures prescribed for protection at work, etc. being applied. 
those concerning the micro-climate in primary and auxiliary work facilities in terms of health and safety at work; and for the preliminary and periodical medical examination of workers and as a result of accidents at work, diseases related to work and workplace fatalities.

In respect of preventive care and protection, great importance is also attached to reporting accidents and injuries at work, as well as of the immediate dangers that threaten the safety of workers at work. Notifications are made officially by the delivery of a special report written by the employer to the competent republic-level administrative body for labour inspection. The employer is obliged to submit a report immediately, but no later than 48 hours after an event. On receipt of such a report, the authorised labour inspector may come to the scene and immediately investigate the situation on the spot, with the power to take the necessary measures to remove the factors that led to the accident or the immediate danger which was threatening the safety of workers at work.

The Law on Safety and Health at Work contains a group of provisions that stipulate the rights and obligations of employees concerning their safety at work. According to the Law, employees are entitled to participate in the determination and the improvement of their working conditions and their working environment, i.e. to propose the taking of new protection measures or to enhance the existing ones. The legislator has prescribed such a right for workers to provide a means of improving working conditions with employers and to improve forms of work organisation, as well as to protect the health and safety of workers.

The Law obliges each employee to comply with the prescribed safety measures and measures for the protection of health at work, and to use the equipment set aside for this purpose. An employee who fails to comply with these measures and does not use safety equipment at work, thereby endangering their lives and health, the lives and health of other workers, the employer's property or the environment and nature are committing a major labour offence and can be removed from the workplace or from work with the employer.

In order to protect employees from immediate dangers to their life and health in the performance of their tasks and duties, the Law prescribes the right for every worker who has noticed an immediate threat to life or health, where the prescribed protection measures at work have not been taken, to refuse to work until the causes that jeopardise the safety of the job have been removed. In this connection, the employee has the right to refuse to work with work equipment which does not have the appropriate protective equipment or from which such equipment has been removed. Additionally, the employee has the right to refuse to work in a workplace in which there is a risk of occupational and other diseases until such dangers have been eliminated.

In all these cases, the law sets down an obligation for the employee to notify the employer and the representative for workers' safety of their reasons for refusing to work. The employer is obliged immediately to take measures to remove the causes that directly endanger the life or health of the employee. In the event of a dispute regarding the reasons for an employee's refusal to work, the employer may ask for mediation by the administrative body in charge of labour inspection, which is obliged to inspect and determine the identified condition written in the notification to the employer and worker 
safety representative. However, the Law does not prescribe a deadline within which the inspection body must notify these two entities about the identified facts concerning the employee's refusal to work. In our view, this needs to be done immediately, or at least within 24 hours of determining the facts.

The Law on Safety and Health at Work, within the system of the protection of workers in performing their tasks and duties prescribed by the employer, contains an obligation for any employer who employs more than ten workers to provide credentials for a representative on workplace safety and health. This person enjoys specific legal protections as regards their employment that are substantially the same as those enjoyed by trade union representatives in accordance with the law and the collective agreement. Such a safety representative is elected by workers from among their ranks in a trade union meeting of the majority trade union or at a mass meeting of employees. Where the employer has 101 to 500 employees, two representatives are elected, while three may be elected in employers who have 501 employees or more.

The representative of workers for health at safety at work has the following rights:

- to tour the workplace to gain a perspective on the situation regarding work safety

- to converse with the employer about the needs and problems of health and safety at work and about the health and working conditions of workers

- to inform the labour inspectorate and require its mediation and supervision in cases where workers' rights in connection with health and safety at work are being violated

- to request from the employer information regarding the planning and regulation of workers' safety and health; preventive and protective measures and means; occupational illnesses and accidents at work; the examination and testing of equipment and working conditions; the training and development of employees in terms of working safely; the medical examination of workers who are working under specific conditions; the measures taken against workers and in respect of the other employer rights or powers set out in the act; and so on.

Within the function of control and oversight of the implementation of the provisions included in the Law, provisions are set out within it for inspection. Such oversight is, basically, the responsibility of the Ministry of Labour and Social Policy and is, in the first place, implemented by the National Labour Inspectorate in accordance with the provisions of this Law and the Law on Labour Inspection.

The inspection activities of the Inspectorate of Labour are exercised by authorised inspectors.

For the purposes of protection and the prevention of accidents, injuries and occupational diseases and illnesses, the labour inspector ${ }^{6}$ has, within a certain timeframe and in order to eliminate the irregularities and defects that can endanger the lives and health of workers, the following rights:

- to order the employer to bring forward a special programme for incremental compliance with particular conditions under the regulations for the protection of safety and health at work

6 The operation of labour inspection is within the competence of the Labour Inspectorate of the Republic of Macedonia (see Law on Inspection of Labour Official Gazette of RM No. 35/97). 
- to order the application of generally-recognised measures of protection that can remove dangers at work or reduce the potential for damage to the health of workers

- to order the prohibition of work, workplaces and working tools, or of technological processes in whole or in part, if $\mathrm{s} /$ he determines the existence of a danger to the life and health of workers

- to order the prohibition of work in other cases where work or the technological process is against the prescribed measures of safety and health protection of workers.

These prohibition orders are formally ordered by the decisions of the labour inspectors themselves. The employer has the right of appeal against their decisions but, given the nature of things, this does not stop the execution of the decision. ${ }^{7}$

Besides the Law on Safety and Health at Work, measures to ensure the safety and protection of the health of workers at work are prescribed by other laws of the Republic of Macedonia.

\section{Law on Labour Relationships}

Among these other laws, certainly the most important is the Law on Labour Relationships (the Labour Law). ${ }^{8}$ This Law, by the provision of Article 42 in relation to the exercise of the right to health and safety at work, underlines the application of the provisions of the Law on Safety and Health at Work.

The Law contains special provisions for the protection of women, young people and workers with disabilities. These provisions are specifically aimed at protecting the health of these categories of people given the particular abilities they possess in terms of gender, age and reduced working ability. ${ }^{9}$ These provisions are not contained in the Law on Safety and Health at Work because they appear in the role of leges speciali to the provisions of this Law.

In addition to this law, there are a number of others containing special provisions for the exercise of the right to health and safety at work. These laws, as with the Labour Law, also take on the role of leges speciali regarding the Law on Safety and Health at Work.

\section{The Law on the Environment}

The Law on the Environment ${ }^{10}$ prescribes the measures and the procedures which actual and legal entities must undertake to protect the environment and also nature in

7 According to the administrative legal regulations, appeals do not stay the execution of decisions through which hazards to the life or health of people, or to the property of legal entities and individuals, as well as disruption in the economy, to public order, etc. may be stopped or eliminated.

8 The clean text of the Law is published in the Official Gazette of RM No. 54/13.

9 See Article 160 and 180 of the Law.

10 The clean text of the Law is published in the Official Gazette of RM No. 53/05. Soon after this text was published, amendments were published in the Official Gazette of RM No. $96 / 2000$, while further changes and additions were published in the Official Gazette of RM No. $45 / 2002$. 
general. Given that the human environment is often a work environment, in which employees perform numerous tasks and work duties for employers, this Law, with its many provisions, also protects the lives and health of workers.

The Law prescribes a number of measures aimed at protecting the environment concerning threats to health and safety in connection with discharges or the emission of municipal and industrial hazardous and harmful substances as regards their manufacture, use, transportation, trade, storage, neutralisation and disposal. The application of these measures ensures that the performance of these activities must be conducted in a manner and under conditions which do not endanger the lives and health of people and the survival of flora and fauna; do not pollute the environment and nature in the process of its day-to-day flow; and, where defects occur, that these are tackled in accordance with the criteria and the conditions laid down by law and the international conventions and treaties which the Republic of Macedonia has ratified or to which it has acceded.

\section{Law on the Protection of Explosive Materials}

The Law on the Protection of Explosive Materials ${ }^{11}$ prescribes the measures which must be taken by private citizens and those with corporate identity who produce, transport or use explosives in the course of their ordinary operations. Taking measures to protect the lives and health of workers, and others, from serious injury or death to which they may be exposed should explosive substances be handled or used in such a way that is contrary to the measures prescribed by the Law, makes a clear contribution to workers' safety.

\section{Law on the Quality of the Air}

The Law on the Quality of the Air ${ }^{12}$ outlines provisions and measures which must be taken, again by private citizens and those with corporate identity, in order to protect against the pollution of the air as an element of the natural environment which is of essential importance for the survival of people and wildlife.

\section{The Law on Protection Against Ionising Radiation and Radiation Safety}

The Law on Protection Against Ionising Radiation and Radiation Safety ${ }^{13}$ prescribes the measures to be taken where employers use working tools and equipment which, in the course of their use, emit ionising radiation. This is a new law that has existed in the legal system of the Republic of Macedonia for a relatively short time. Its passing has resulted in the protection of workers and others from ionising radiation which are, day-to-day, more prevalent in the environment and which pose a serious threat to the health and lives of people.

11 This Law was passed at the beginning of 1978 by the Parliament of the former Socialist Republic of Macedonia, the text of which was released in the Official Gazette of SRM No. 4/78. Amendments and supplements to the Law were published in the Official Gazette of SRM Nos. 10/78, 51/78, 36/90 and the Official Gazette of RM No. 12/93.

12 Official Gazette of RM No. 67/94.

13 Official Gazette of RM No. 48/02. 


\section{Law on Protection Against Smoking}

Through the Law on Protection Against Smoking, ${ }^{14}$ people are protected from the harmful effects of the smoking of tobacco and other tobacco products, while the Law also seeks to preserve a healthy environment against the levels of pollution which arises from smoking. The legislator, understandably so as regards the environment in which the provisions of law might function, implies public facilities.

\section{Law on Labour Inspection}

The Law on Labour Inspection ${ }^{15}$ is, without a doubt, a key law in the system of the control and development of the protective functions of those social institutions which are intended to protect workers against violations of the laws and other regulations that comprise the labour legislation of the Republic of Macedonia. This legislation, selfevidently, belongs among the laws which seek to protect workers at work. According to the provisions of Article 1 of this Law, labour inspection activities are carried out by the National Labour Inspectorate. Its supervision operates within the context of focused labour inspections carried out by specialist labour inspectors. The Law prescribes the implementation of labour inspection procedures and the handling of cases springing from the detection of violations of laws contained within the labour legislation of the Republic of Macedonia.

\section{Law on Sanitary and Health Inspection}

The Law on Sanitary and Health Inspection, ${ }^{16}$ in the context of the system of employers' responsibilities vis-à-vis the protection of workers at work, represents a lex specialis in relation to the Law on Labour Inspection. This Law defines the responsibilities, powers and organisation of the State Sanitary Inspectorate, a body that supervises the execution of laws and regulations in the field of the sanitary hygienic and epidemiological health of the population. The duties of the Inspectorate are carried out by republican sanitary and health inspectors. Article 10 of the Law stipulates in detail the powers of such inspectors in cases where they detect violations of these laws or of other republican normative regulations.

Besides these laws in the legal system of the Republic of Macedonia, there are others that regulate specific issues regarding the protection of health and lives concerning the injuries and occupational illnesses which may arise from the performance of certain activities. Due to limited space, however, we are unable to address all of them.

14 Under the notion of 'public premises' within the meaning of the Law (Article 2), this implies facilities in which are performed educational and other similar activities and facilities concerning the residential accommodation of children and students; facilities in health and social institutions; indoor and outdoor premises where sports competitions are held; cultural events and other public gatherings; facilities for public passenger transport; facilities in which food is produced, prepared, served, sold and consumed; rooms in which appointments and meetings are maintained; and other premises - halls, offices, waiting rooms, corridors and so on - that are determined by an act of the legal entity in accordance with the Law.

15 The Law is published in the Official Gazette of RM Nos. 35/97 and 29/02.

16 The Law is published in the Official Gazette of RM No. 71/06. 
Provisions for occupational safety are also set out in collective agreements. Among these, certainly the most important are the General Collective Agreement for the Republic of Macedonia; the General Collective Agreement for the Private Sector in the Economy in the Republic of Macedonia; and the General Collective Agreement for Civil, Judicial and Local Authorities. These agreements, as regards their provisions on health and safety at work, basically document references to the standards to which employers and employees are directed as regards the protective provisions embodied in the laws which regulate their work.

\section{Actual situation in the Republic of Macedonia regarding the application of the legislation on health and safety at work}

The legal system of the Republic of Macedonia contains an extensive qualitative and normative framework on health and safety at work.

Unfortunately, provisions within this general regulation are insufficiently applied in practice. The reasons for this can basically be condensed into three groups, these being:

- lack of a general culture about the rule of law

- lack of organisational discipline

- lack of resources to purchase and maintain funds for occupational safety and to finance the enforcement measures necessary for this purpose.

Regarding the first reason (the lack of a common legal culture), the most illustrative example is the application of the anti-smoking law. Almost all averagely-educated citizens of the Republic of Macedonia are informed about the existence of this law and the prohibitions which it contains in relation to smoking in public places. But, in practice, the situation is more worrying: it is simply rare to find people - smokers - who are willing to comply with the provisions of this law and who do not smoke in the public facilities that are covered by the Law's prohibitions. It is normal to smoke in the corridors of public institutions, in trains, in restaurants, in stores that sell food, etc: few of our citizens are aware that the use of their freedom to smoke restricts the freedom of others to stay in a healthy and clean environment.

In addition, many employers simply do not prescribe and take the necessary measures to secure protection at work, believing that it is a luxury that can not be realised. In turn, workers have not insisted on their employers taking these measures either for the same reason or simply because they do not want to attract employers' enmity.

The lack of discipline in work is closely related to the general lack of a culture of the rule of law. Many of our workers are simply not aware of the need for discipline in the conduct of their business and work tasks in order to protect their health and their lives. Unaware of this, they do not adhere to employers' prescribed measures and guidelines on the protection of safety and health. This often leads to injuries, many of which end fatally. If we cast a simplistic view on the behaviour of employees, we notice that there are few who wear protective helmets which is officially mandatory when involved in construction work.

The lack of resources is also an important reason for the failure to take the prescribed measures for protection at work. Many employers engage in business with modest 
material resources that are often insufficient for the payment of wages to workers. In many of them, the primary desire is for quick profits and enrichment. Obsessed with that goal, they reduce production costs to a minimum. So, funds and equipment for protection at work are among the first to be hit.

These social conditions impose the need for the engagement and inspection services of the competent prosecution authorities to be enhanced. By this means we will not, of course, completely remove all the deficiencies in the system of protection at work, but there is no doubt that the numbers of these will be greatly reduced.

\section{Conclusion}

From a normative-legal perspective, Macedonia has a comprehensive and quality normative regulation of health and safety at work. Of course, nothing in the world is so perfect that it does not have a need for, and should not be, upgraded and improved. That goes for normative regulation in this area. Frequent amendments to the laws and regulations of the legislation, relevant to achieving the right to health and safety at work, is an obvious indication of the efforts of the state bodies of the Republic of Macedonia to perfect the normative regulations in order that these might be fully compatible with the emerging need to protect the lives and health of workers and citizens against harmful effects and impacts incurred in the performance of their duties and tasks in the economy and in other social activities. However, the normative framework will not be perfect and will turn out to be just words on paper if the state does not provide appropriate mechanisms with which it might be respected.

The primary protective functions and institutions of the state - largely, inspections and the prosecution authorities (police, prosecution and courts) - certainly play a significant role in this regard. What is much more important, of course, is the role which must be played by the educational institutions of society (family, schools, universities, etc.). These need to intensify to the maximum their educational work aimed at making citizens, especially young people, develop the right attitudes towards work and, in particular, to make them feel the need to respect social and work disciplines and to develop a general culture of the rule of law. This is, without doubt, the right way to reduce the number of injuries and deaths at work and, of course, to establish an effective system of the protection of health and safety at work in Macedonian society.

\section{References}

Cucić, V et al. (2000) Social Medicine Contemporary Administration: Belgrade.

Collection of Human Rights International Documents, Pearson Peacekeeping Centre, Cornwallis, Nova Scotia: Canada, 2001.

Đorđević, J (1979) Constitutional Law Institute of Economics and Social Activities: Skopje.

Dimitrijević, V and M. Paunović (1977) Human Rights Belgrade Centre for Human Rights: Belgrade. 
Gatarić, Đ (1988) Administrative Law - the Special Part Contemporary Administration: Belgrade.

Micović, P et al. (1986) Social Medicine Medical Books: Beograd, Zagreb.

Pusić, E (1989) Social Regulation Globus: Zagreb.

Constitution of the Republic of Macedonia.

Laws and other regulations concerning work and the legislation of the Republic of Macedonia regarding health and safety at work 